\title{
Horacio Ciafardini, una vida entre la ciencia y la revolución. Sistematización de su trayectoria política e intelectual (1942- 1984)
}

\author{
Horacio Ciafardini, a life between science and revolution. Systematization of his politic \\ and intellectual career
}

\section{Rubio Matias J.}

\author{
Docente y becario de investigación de la Universidad Nacional de Lujan (UNLu) \\ Doctorando en Ciencias Sociales en la UNLu \\ rubiomatias08@hotmail.com.ar
}

\begin{abstract}
Resumen: En este trabajo sistematizamos los avances alcanzados en una investigación en curso que pretende abordar la trayectoria política e intelectual del economista argentino Horacio Ciafardini (1942-1984). Al tratarse de un trabajo en desarrollo y ante la ausencia de escritos que sistematicen esta información, en nuestra reconstrucción ponemos énfasis en los aspectos formales de su vida y no en el análisis de su producción intelectual.
\end{abstract}

Palabras clave: Horacio Ciafardini; economía marxista; Partido Comunista Revolucionario.

\begin{abstract}
In this article we arrange the accomplishments of an investigation in progress which aims to address the political and intellectual career of the Argentinian economist Horacio Ciafardini (1942 - 1984). Considering it is an ongoing work and in the absence of written documents that address that information, our reconstruction is emphasized in the formal aspects of his life rather than in the analysis of his intellectual performance.
\end{abstract}

Keywords: Horacio Ciafardini; Marxist economy; Revolutionary Communist Party. 


\section{Introducción}

En este trabajo nos ocupamos de sistematizar los avances de una investigación en curso sobre la trayectoria política e intelectual del economista argentino Horacio Ciafardini (1942-1984). Este tema se enmarca en una investigación doctoral en Historia que lo excede y que tiene por objeto el estudio de las producciones e interpretaciones historiográficas de la Historia Argentina elaboradas por el Partido Comunista Revolucionario (PCR) desde sus orígenes (1967) hasta su $5^{\circ}$ Congreso (1987). Como elementos complementarios, incorporamos dos líneas de trabajo que, en nuestra consideración, nos permitirán abordar el tema de forma más exhaustiva. La primera de ellas es la reconstrucción y análisis de la línea estratégica y programática del partido en este período, y, la segunda, el abordaje de diferentes trayectorias políticas e intelectuales de militantes del partido; es decir, según nuestra perspectiva, de los productores de textos significativos.

En este sentido, reconstruimos, a grandes rasgos, los principales aspectos de su vida y su producción intelectual, sin profundizar en esta última por cuestiones de espacio. Para nuestro análisis prestamos particular atención a los aspectos biográficos, a los coyunturales (en tanto elementos determinantes de la forma que fue tomando la producción política e intelectual del autor), los espacios y momentos de formación, el universo familiar y laboral, los viajes y las tramas de amigos (DI PASQUALE y SUMMO, 2015: 11-19). Para ello trabajamos, por un lado, con entrevistas y archivos privados de personas que estuvieron vinculadas a él $\mathrm{y}$, por otro, con sus publicaciones y producciones. En cuanto al método de exposición, respetamos el orden cronológico y, en relación con este, buscamos identificar distintos momentos en el desarrollo de su trayectoria a fin de componer un cuadro general.

\section{2-1970: de Rosario a Varsovia, ida y vuelta}

Horacio Ciafardini nació el 27 de octubre de 1942 en la ciudad de Rosario, Provincia de Santa Fe, en el seno de una familia de clase media alta profesional, sin participación política, que ocupaba un departamento a dos cuadras del monumento a la bandera. Su padre fue Luis Alberto Ciafardini (1902-), su hermano mayor Eduardo Luis 
y su madre Hebe Adela Meneclier (1909) ${ }^{1}$, “a la que se le atribuía una temprana obsesión por los estudios y habría sido la Directora del Liceo de Señoritas Bernardino Rivadavia en la calle Boulevard Oroño" una institución de prestigio en la Rosario de la época $^{2}$. Las escasas referencias sobre su infancia lo muestran con un espíritu inquieto y aplicado: un niño lector y estudioso de diversos idiomas ${ }^{3}$. Una vez terminados los estudios secundarios, de los que egresó como "Bachiller en Ciencias Comerciales" de la Escuela Superior de Comercio Libertador General San Martín, ingresó a la Universidad Nacional del Litoral (UNL) a estudiar la carrera de Contador Público y Auxiliar de Psicología, de las que egresó en 1963 y 1964. Al mismo tiempo habría cursado algunas materias de las carreras de Letras, Derecho e Historia. En otro plano, su época universitaria también correspondió con el estudio certificado de idiomas que le permitieron, una vez graduado, conseguir becas para estudiar en Europa: su conocimiento de inglés fue evaluado por la Universidad de Cambridge y el de francés por la Alliance Françoise que lo seleccionó como "el mejor examen final en Francés y Literatura Francesa" y le otorgó una beca para ir a estudiar a Paris en $1964 .^{4}$

Junto con la obsesiva dedicación a los estudios, durante su paso por la UNL habría sido un destacado activista del reformismo, llegando a ocupar una secretaria en la Federación Universitaria del Litoral (FUL) ${ }^{5}$, y, entre 1960 y 1962, habría sido militante de una de las secretarias del Partido Socialista Argentino (PSA) ${ }^{6}$. En 1961, en carácter

\footnotetext{
${ }^{1}$ Los nombres de su familia fueron encontrados en el legajo docente de Horacio Ciafardini al que pudimos acceder en la E.E.M N 432 "Bernardino Rivadavia", donde anteriormente funcionó el "Liceo Nacional de Señoritas Bernardino Rivadavia". Legajo de Horacio Ciafardini, E.E.M N 432 "Bernardino Rivadavia". 1961-1964.

${ }^{2}$ Los testimonios recolectados coinciden en indicar que Hebe Adela Meneclier habría sido rectora de dicha institución. Sin embargo, en el archivo de la actual E.E.M N ${ }^{\circ} 432$ "Bernardino Rivadavia" no hallamos documentación que avalara, ni desmienta, dicha información. Entrevista a Edgardo Ferrer, realizada por el autor en septiembre de 2019. Entrevista a Aldo Mangiaterra, realizada por el autor en septiembre de 2019. Entrevistas a Osvaldo Barsky, realizadas por el autor en julio y agosto de 2019.

${ }^{3}$ En el Archivo personal que guardaba María Inés Olivella, quien fuera su esposa, se encontraba un premio al mejor lector del año, de una librería de su barrio. Lamentablemente, avatares ajenos a quien escribe determinaron que dicho documento no haya podido ser consultado nuevamente para dar cuenta de la referencia exacta.

4 "Breve reseña sobre mi carrera", Horacio Ciafardini, s/f.

${ }^{5}$ Diversas fuentes coinciden en señalar que H. Ciafardini habría ocupado un cargo directivo en el órgano de representación estudiantil, sin dar precisiones respecto al periodo, al cargo especifico y al nombre de la organización dentro de la que actuó o militó. Por ejemplo: Salvatore sostiene que su "participación en las luchas estudiantiles lo llevaron a ocupar el secretariado de la Federación Universitaria del Litoral" (Salvatore, 1985: 22) y Edgardo Ferrer que durante su época de estudiante llegó a ejercer "el cargo de secretario de la Federación" (Ciafardini, 2002: 22).

${ }^{6}$ El PS, fundado en 1896, se fracturó en 1958 dando origen a dos organizaciones distintas: el Partido Socialista Argentino (PSA) y el Partido Socialista Democrático (PSD). Mientras el primero comenzaría un proceso de radicalización, integrado por Alfredo Palacios, Alicia Moreau de Justo, Carlos Sánchez Viamonte, José L. Romero, Ramón Muñiz y David Tiffenberg entre otros; el PSD encarnaría el ala más liberal conservadora bajo la conducción de Américo Ghioldi, Nicolás Repetto, Juan A. Solari, Teodoro
} 
de representante del Comité de Solidaridad con Cuba, a raíz de su encuadramiento como militante socialista, habría viajado a la isla en el contexto de la invasión a Bahía de Cochinos ${ }^{7}$. Carlos Altamirano, por su parte, recuerda haberlo conocido en Corrientes, hacia el '62 o '63, como un activista universitario ligado al sector del Movimiento Nacional Reformista (MNR) que orientaba Ariel Seoane, quien entre 1963 y 1965 fue presidente de la Federación Universitaria Argentina (FUA) y seria reconocido posteriormente como un afiliado secreto del Partido Comunista (PC) ${ }^{8}$. Mientras estudiaba, además de la actividad política y el trabajo en colegios secundarios (19611964), H. Ciafardini desarrolló una intensa actividad académica: obtuvo "becas breves de las Universidades Nac. De Córdoba (1961), de Concepción (Chile, 1963) y de la Republica (Montevideo, 1964)" y en 1964 fue ayudante alumno, por concurso, "de la catedra Sociología en la Facultad de Filosofía y Letras" de la UNL (CIAFARDINI, Curriculum Vitae, febrero de 1976).

En 1964, una vez recibido, fue becado por Gobierno Francés para viajar y seguir formándose en economía. En Paris se integró al grupo de investigación dirigido por François Perroux (1903-1987) que trabajaba en la teoría de los Polos de Desarrollo. De esta experiencia, recuerdan sus amigos, Horacio C. había quedado un poco desilusionado, "se había aburrido de sobremanera, poco serio decía" (Entrevistas a Osvaldo Barsky, realizadas por el autor en julio y agosto de 2019). Por otro lado, también entre 1964 y 1966, desarrolló “Investigaciones Personales” bajo la dirección del economista marxista Charles Bettelheim "acerca de la cuestión de las prioridades sectoriales en la planificación" (CIAFARDINI, Curriculum Vitae, febrero de 1976). Sin embargo, a pesar de concluir sus compromisos formales con la beca, Horacio siguió en

Bronzini y Jacinto Oddone entre otros. Según el testimonio de Osvaldo Barsky, en los "60 en que nos cruzamos en el Centro de Estudiantes" Horacio Ciafardini habría participado "con nosotros [PC] en la Lista Renovación. Es en ese período es que lo recuerdo como militante del Partido Socialista, creo que en la secretaria Tiffenberg siendo secretario de esa fracción en Rosario (creo)”. Por otro lado, Miguel Ángel Ferrari asegura que, con H. Ciafardini, militaron "en el Partido Socialista Argentino, creado con la división del Partido Socialista de 1958, en el Centro Asturiano de la ciudad de Rosario" entre 1960 y 1962 y recuerda que "solía dar cursos de marxismo entre los compañeros del partido". Entrevistas a Osvaldo Barsky, realizada por el autor, en julio y agosto de 2019. Comunicación personal con Miguel Angel Ferrari, septiembre de 2019.

${ }^{7}$ Según Osvaldo Barksy, allí "fue dirigente del movimiento de solidaridad con Cuba (creado con la invasión de Bahía de Cochinos) y de la Federación Universitaria del Litoral”. Su mujer, María Inés, coincidió en advertir su "pasado en el socialismo" y su "viaje a Cuba, de muy joven". Entrevistas a Osvaldo Barsky, realizada por el autor, en julio y agosto de 2019. Entrevistas a María Inés Olivella, realizadas por el autor entre diciembre de 2018 y abril de 2019.

${ }^{8}$ A. Seoane era, para casi todos los entrevistados, un afiliado secreto del PC que ocupaba un lugar importante en la dirección del MNR. Luego sería unos de los fundadores del Movimiento Estudiantil Nacional de Acción Popular (MENAP), un desprendimiento por izquierda del MNR. Entrevista a Carlos Altamirano, realizada por el autor en octubre de 2019. 
Europa: entre 1966 y 1969 fue becado por el gobierno polaco y, del otro lado de la cortina de hierro, en 1967 y 1968, tomó seminarios sobre planificación económica en Berlín y en Belgrado (Entrevistas a Osvaldo Barsky, realizadas por el autor en julio y agosto de 2019).

En 1968, después de participar en Sofía, Bulgaria, del Festival Mundial de la Juventud y los Estudiantes por la Paz y la Amistad se trasladó a la ciudad de Praga. Allí, junto a "el Gringo [Buzzi, de la Facultad de Ciencias Económicas de la UNL], delegado permanente de la FUA [...] en la UIE (Unión Internacional de Estudiantes)", Aldo Mangiaterra "delegado de la FUA al Festival y a una reunión de la UIE", "Carlos, médico, oriundo de Buenos Aires, becado en Checoslovaquia y su esposa Ana" y “García, de Buenos Aires, delegado del gremio telefónico a ese Festival” fue testigo de la invasión soviética a Checoeslovaquia. Durante aquellas agitadas jornadas, Horacio ofició de traductor a sus compañeros de viaje: leía en voz alta los volantes que circulaban, contaba que decían los comunicados radiales y resumía los contenidos de las conversaciones que se producían en la calle entre los checoeslovacos y los soldados rusos. ${ }^{10}$ Según los testimonios, Horacio en aquellos viajes había aprendido diversos idiomas en muy poco tiempo sobre la base de estudiar en profundidad las lenguas madres, como el latín y el griego, entre otras: lo que le permitía desenvolverse sin inconvenientes tanto para los quehaceres cotidianos como para las discusiones políticas o académicas. ${ }^{11}$

Entre 1966 y 1969 vivió en Varsovia, Polonia, donde trabajó junto a Michał Kalecki y se doctoró en la "Ecole Centrale de Planification et de Stadistique" bajo la dirección de "E. Gorzelak"12. En la "Faculté d'Economie de la Production" redactó y defendió su tesis titulada "Quelques aspects du capitalisme dans l'agriculture d'Amerique Latine"13. Al mismo tiempo, se especializó en el área de la planificación económica, particularmente en los países del bloque soviético.

Aún en Varsovia escribió y envió para publicar un artículo titulado Algunas deficiencias de la planificación en la práctica de los países socialistas (1970) a la revista Economía y Administración de la Universidad de Concepción de Chile, donde

\footnotetext{
${ }^{9}$ Militante de la Federación Juvenil Comunista (FJC) de Rosario durante los años 1960.

10 Aldo Mangiaterra, "50 años de la Primavera de Praga" en: https://aldomangiaterra.blogspot.com/2018/08/a-50-anos-de-la-primavera-de-praga.html

${ }_{11}^{11}$ Entrevistas a Osvaldo Barsky, realizada por el autor, en julio y agosto de 2019.

${ }^{12}$ No logramos dar con información sobre este docente.

${ }^{13}$ En su curriculum personal, fechado en febrero de 1976, señala que la traducción correcta de su título seria “Algunos aspectos del capitalismo en la agricultura de América Latina". CIAFARDINI, Horacio. Curriculum Vitae, Buenos Aires, febrero de 1976.
} 
había estado como becario en 1963. Enmarcado en su formación de los últimos años, el articulo aborda, a raíz del análisis de la experiencia acumulada hasta ese momento en los países de la órbita soviética, el problema de la planificación económica desdoblándolo en dos aspectos: la construcción de los datos sobre los cuales se basa la planificación y los métodos de construcción de los planes.

\section{0-1971: la vuelta al país, la incorporación partidaria y el trabajo intelectual}

Una vez concluidos los estudios de posgrado, Horacio Ciafardini regresó al país y se asentó en su ciudad natal. Allí volvió a integrarse en la vida política e intelectual rosarina, incorporándose a diversas actividades de lectura y discusión que giraban en torno al ámbito universitario y eran animadas por jóvenes militantes del comunismo y la izquierda marxista. En ese contexto, dictatorial, la entrada formal al trabajo universitario estaba totalmente vedada para cualquiera que pudiera despertar sospechas de marxista, de modo que el ámbito de discusión y elaboración fue para él el del activismo de izquierda. En ese plano, se agrupó con una serie de personas que determinaron su doble inserción: en el medio intelectual extrauniversitario y en la estructura política del Partido Comunista Revolucionario (PCR) ${ }^{14}$, cuyos miembros fundadores de la provincia de Santa Fe habían sido compañeros de estudio y militancia en la UNL.

Carlos Alberto Cristiá ${ }^{15}$, quien lo habría conocido en Francia, fue el encargado de contactar a un conjunto de jóvenes universitarios y profesionales de izquierda en torno a Horacio Ciafardini, quien era promocionado como un joven erudito que regresaba al país, luego de una prolongada formación en el exterior, con novedades teóricas y un sólido conocimiento del marxismo. Por otro lado, en ese contexto y medio social se incorporó a las filas del PCR, del que O. Barsky ya formaba parte y asegura haberlo afiliado.

\footnotetext{
${ }^{14}$ Sobre los orígenes y el devenir de esta organización véanse los trabajos de: Marcelo Starcenbaum (2016), Guido Lissandrelo (2018; 2015), Santiago Siskindovich (2017), Juan Manuel Cisilino (2017), Juan Sebastián Califa (2015), Daniel Campione (2008), Isidoro Gilbert (2009), Ruth Werner y Facundo Aguirre (2009), Brenda Rupar (2019) y Rubio (2019; 2018a; 2018b; 2018c; 2017).

${ }^{15}$ Según los testimonios, Carlos Alberto Cristiá era un joven proveniente de una familia pudiente de la capital santafesina que habría iniciado su militancia en grupos elitistas y conservadores (anti reformistas) durante su etapa de estudiante universitario. Sin embargo, al concluir sus estudios habría sido becado en Francia, en el contexto de la radicalización política, y habría vuelto al país asumiéndose marxista. Entrevista a Edgardo Ferrer, realizada por el autor en septiembre de 2019.
} 
Su militancia partidaria, en este período, se habría desarrollado, fundamentalmente, en el plano de la propaganda y la formación teórica de los militantes. Centralizándose en una célula denominada "de Logística" dedicada a las cuestiones financieras y organizativas de la regional Rosario, con la que cumplía el requisito formal para ser considerado parte orgánica de la organización, su actividad central fue desarrollar escuelas de formación para los militantes internos: dedicadas centralmente al estudio sistemático del primer tomo de El Capital (Entrevista a Edgardo Ferrer, realizada por el autor en septiembre de 2019; Entrevista a Aldo Mangiaterra, realizada por el autor en septiembre de 2019). Por otro lado, en este momento aparecieron sus primeras publicaciones en la revista teórica del PCR, Teoría y Política. En una seguidilla que va desde mayo a diciembre de 1971 se publicaron tres reseñas bibliográficas que en parte contienen sus preocupaciones en aquella época. Como veremos a continuación, estas tienen una estrecha relación con las producciones realizadas en otro espacio de sociabilidad que, para Horacio Ciafardini, bien podrían pensarse como parte de lo mismo.

En 1970, con Carlos Cristiá, Edgardo Ferrer, Osvaldo B., y Roque Caggiano formaron el Centro de Trabajadores Intelectuales (CTI $)^{16}$. Este funcionó, entre 1970 y 1971, en unas oficinas ubicadas en el edificio donde se encontraba el estadio de boxeo Rosario Norte que eran propiedad del ingeniero Pedro J. Cristiá, padre de Carlos, quien había presidido la Confederación General Económica (CGE) de Rosario y recibía infinidad de publicaciones de instituciones estatales como el Instituto Nacional de Tecnología Agropecuaria (INTA) que pudieron consultar y analizar. Además, los testimonios coinciden en señalar que, la mayoría de las actividades y gastos se sostenían por el aporte económico del joven Carlos Cristiá.

El origen del centro, según Edgardo Ferrer, se remontaría al conflicto surgido al interior de un grupo de estudios donde se encontraba Oscar Braun (1940-1981) ${ }^{17}$. Mientras este último quería focalizar los futuros encuentros del grupo en la lectura de autores neo keynesianos, como Joan Robinson, H. Ciafardini habría propuesto a sus colegas dedicarse al estudio de El Capital y otros autores que llevaban adelante las discusiones más encendidas del marxismo contemporáneo. Lejos de pretender fundar un grupo intelectual o editorial, el CTI fue, simplemente, un sello que estos jóvenes le

\footnotetext{
${ }^{16}$ Una figura que no aparece mencionada en los documentos del CTI, pero los entrevistados recuerdan siempre presente en sus lugares de trabajo y estudio era Jorge Olivella, un contador rosarino que sería cuñado de H. Ciafardini.

${ }^{17}$ Economista de origen bonaerense ligado a las organizaciones armadas de la izquierda peronista.
} 
pusieron a su círculo de estudios para poder firmar las publicaciones que producían y editaban (Entrevista a Edgardo Ferrer, realizada por el autor en septiembre de 2019).

Allí, en largas e intensas jornadas de trabajo, se realizaban reuniones donde se discutían las grandes obras de la teoría económica y los debates contemporáneos: Adam Smith, David Ricardo, Karl Marx, Rosa Luxemburgo, Nicolai Bujarin, Rudolf Hilferding, Piero Sraffa, Michael Kalecki, Charles Betthelheim, Maurice Godelier y Maurice Dobb, entre otros. Al respecto Osvaldo Barsky sostiene que tal experiencia habría sido un "verdadero posgrado en teoría económica" cuyo nivel estuvo determinado por formación adquirida por H. Ciafardini en su estadía europea, lo que le permitía destacarse como cursillista y polemista entre sus pares ${ }^{18}$. Además, en este ámbito de formación, a raíz de la lectura y la discusión colectiva, habrían comenzado a estructurar, con un prominente protagonismo de H. Ciafardini, un método de abordaje de El Capital, a partir del cual armaron un curso. Este, según Osvaldo Barsky, constaba de tres partes, de aproximadamente tres meses de duración cada una; la primera estaba dedicada al análisis de la teoría del valor, la plusvalía y la ganancia, sobre la base del tomo 1 y 3 de la obra; una segunda parte donde se abordaba la distribución de la plusvalía entre diferentes ramas del capital y; una tercera parte, preparada y pensada exclusivamente por H. Ciafardini, que giraba en torno a los textos históricos de Marx, el método de análisis de situaciones concretas, sobre la base de obras tales como La lucha de clases en Francia y El 18 brumario de Luis Bonaparte (Entrevistas a Osvaldo Barsky, realizadas por el autor en julio y agosto de 2019).

Las discusiones de los clásicos marxistas $\mathrm{y}$, particularmente, de los que intervenían en torno a la teoría del imperialismo o proponían variantes al modelo leninista llevó al grupo a profundizar la discusión con Oscar Braun. En ocasión de una visita a la ciudad, al parecer por unas jornadas científicas, Braun fue invitado por el CTI a una sesión para discutir en torno al concepto de "intercambio desigual", que él usaba retomándolo de las formulaciones de Arghiri Emmanuel (1911-2011) ${ }^{19}$. En ese marco, se publicaron tres escritos de Ciafardini que polemizaron con dichas ideas. En mayo de 1971, apareció como Cuaderno $\mathrm{n}^{\circ} 2$ del CTI un artículo escrito por Horacio C. y Carlos

\footnotetext{
${ }^{18}$ Los participantes entrevistados coinciden en señalar que H. Ciafardini estaba muy por delante de ellos en sus conocimientos y su ritmo de trabajo. Incluso debieron "tranquilizarlo" ya que su intención era realizar jornadas de discusión donde siquiera se paraba para almorzar o tomar un café. Entrevistas a Osvaldo Barsky, realizadas por el autor en julio y agosto de 2019. Entrevista a Edgardo Ferrer, realizada por el autor en septiembre de 2019.

${ }^{19}$ Economista marxista griego-francés de cierta relevancia en los años sesenta y setenta por la elaboración y difusión de su teoría del "intercambio desigual".
} 
Cristiá, titulado La explotación imperialista y el "comercio exterior" (1971), que planteó una discusión frontal, pero respetuosa, con el economista peronista.

Luego, en Teoría y Política de 1971 y 1972, aparecieron tres reseñas firmadas con seudónimo que discutieron el mismo problema. La primera de estas, firmada como Héctor Páez, abordó el libro de Braun Desarrollo del capital monopolista en Argentina (1970) planteando una delimitación política y metodológica (CIAFARDINI, 1971d); La segunda, destinada a discutir con H. Jaguaribe, A. Ferrer, M. S. Wionezek y Th. Dos Santos que, en 1969 habían publicado La dependencia político - económica de América Latina, fue en la misma dirección (CIAFARDINI, 1971e); La tercera, que fue una crítica a El problema del intercambio desigual de Arghiri Emannuel, donde se alineó con su profesor Charles Bettelheim (CIAFARDINI, 1972f) y; La cuarta, fue en torno a El tratado de economía marxista de Ernest Mandel, donde impugno algunas inconsistencias teórico-metodológicas (CIAFARDINI, 1971f) De esta manera, se produjo un primer empalme entre su producción y las polémicas teóricas que desarrollaba el partido.

Por otro lado, en el CTI se desarrolló otra línea de investigación sobre la estructura económica latinoamericana y el imperialismo. La iniciativa que marcó este desarrollo fue la elaboración y publicación de Dependencia, integración y monopolios en América Latina (1971). Este libro de doscientas páginas, del que se editaron algunas decenas de ejemplares que distribuyeron gratuitamente por el medio intelectual rosarino, fue producto del concurso convocado por la editorial Fondo de Cultura Económica (FCE) de México sobre el tema "las empresas multinacionales en el desarrollo y la integración de Latinoamérica" que finalmente perdieron. Además, en aquel año Horacio publicó, usando el sello del CTI, dos trabajos que serían sumamente importante para su elaboración y posterior publicación en revistas científicas. Estos fueron "Capitalismo comercial”: ¿concepto cientifico? (1971a) y La revolución mexicana y el desarrollo capitalista en la agricultura (1971b).

La primera inserción laboral de H. Ciafardini estuvo ligada a su vínculo con los integrantes del CTI y fue su incorporación al "Equipo Económico del Grupo de Planeamiento Integral dirigido por Horacio Premoli que tuvo a su cargo los estudios de base de los Planes Reguladores de las ciudades de la Provincia de Santa Fe" donde se desarrollaron estudios del "contexto rural". Horacio, en este trabajo, percibió un salario 
como "Jefe de Campo de la Encuesta a las actividades Productivas del Gran Rosario",20, lo que le aseguró una entrada regular de dinero y la posibilidad de engrosar su extranjerizado curriculum vitae. Allí habrían logrado recolectar "valiosa información proporcionada por la Dirección de Estadísticas de la Provincia de Santa Fe" a partir de la cual advirtieron "que se había producido una importante expansión en la década del 60 de ambas variables [la evolución de la producción y los rendimientos de los principales cultivos], lo que mostraba el desarrollo de grandes transformaciones en el agro santafecino" (BARSKY, 2018: 28). Producto de este trabajo de archivo fue la redacción, junto con Carlos Cristiá de Estudio de campo y elaboración de las cuentas sociales de Casilda para 1969. Metodología y principales resultados (1972), en la prestigiosa revista Desarrollo Económico.

Por otro lado, también en esa instancia escribió, junto con Barsky y Cristiá, Producción y tecnología en la región pampeana (1971) para la serie Polémica del Centro Editor de América Latina (CEAL) (Entrevista a Osvaldo Barsky, realizada por el autor entre julio y agosto de 2019). Según Barsky este trabajo, al centrarse en polemizar respecto a las transformaciones agrarias producidas en la década del '60, constituyó una renovación en los estudios agrarios del país, ya que la mayoría insistía en remarcar el relativo estado de estancamiento y atraso respecto al complejo industrial. El trabajo de los tres jóvenes investigadores retomaba aspectos trabajados por Ciafardini en otros artículos y su tesis doctoral, pero terminó por colisionar con la línea del partido del que formaban parte. Barsky, bajo el seudónimo de Pedro Serdán, había publicado en Teoría y Política un artículo donde profundizaba en esa dirección, lo que le valió una respuesta de miembros del Comité Central y su posterior alejamiento de la organización ${ }^{21}$.

En paralelo, H. Ciafardini, en estos años, rondó la periferia de las instituciones académicas. Por un lado, colaboró, en calidad de economista, con el historiador José Carlos Chiaramonte quien dirigía un grupo de investigación, surgido de una experiencia en la UNL, que trabajó un archivo de los siglos XVIII y XIX ubicado en la provincia de Corrientes. Aunque este trabajo quedaría trunco en aquel momento, los resultados se publicarían años más tarde bajo el título de Mercaderes del Litoral (1991) (Entrevista realizada por el autor a José Carlos Chiaramonte, marzo de 2019). Por el otro, participó en la Asociación de Historia Económica y Social, con su correspondiente colaboración

\footnotetext{
${ }^{20}$ CIAFARDINI, Horacio. Curriculum Vitae, Buenos Aires, febrero de 1976.

${ }^{21} \mathrm{Al}$ respecto véase: Rubio (2018a: 72-75)
} 
en la organización de las jornadas que se desarrollaron en Buenos Aires en 1970 y en Rosario en 1971.

De esta manera, entre 1970 y 1972 Horacio Ciafardini desarrolló su actividad intelectual en dos sentidos: intentando de insertarse en el ámbito académico local y estableciendo lazos político-intelectuales con jóvenes científicos radicalizados que marcarían su derrotero temático de allí en más. Sus primeros trabajos, por un lado, auguraban una profundización en lo correspondiente a la estructura económica y social del país y la economía teórica y, por el otro, un abandono de las discusiones en torno a la planificación económica en las economías socialistas ${ }^{22}$.

\section{2-1976: la inserción académica y el desarrollo de una ciencia "útil"}

Entre 1972 y 1973, cuando la salida electoral de la dictadura se consolidaba, Horacio C. ingresó a trabajar en diversas instituciones académicas que determinaron su inserción laboral plena en las universidades nacionales. En 1972 fue profesor visitante en la Universidad Nacional de Rosario en dos oportunidades: en la Facultad de Filosofía y Letras para brindar un seminario en la carrera de Historia que, según lo que varios testimonios indican, giró en torno a la lectura de El Capital de Karl Marx, y para brindar, en conjunto con otros docentes, un curso denominado "Elementos de economía para el análisis espacial” en la Facultad de Arquitectura y Urbanismo.

Al mismo tiempo, H. Ciafardini fue convocado a formar parte y concursar en la Universidad Nacional del Sur (UNS) radicada en la ciudad bonaerense de Bahía Blanca. La invitación habría provenido de Roberto Domech, quien se encontraba organizando "la carrera de economía junto a José Luis Caraggio, Enrique Melchior, Carlos Barrera (todos graduados de la Universidad de Grenoble, Francia, que se habían especializado en economía regionalista con Gambarotta)" y realizando una búsqueda por todo el país de científicos que se ajustaran al perfil de la carrera (Entrevista realizada por el autor a José Carlos Chiaramonte, marzo de 2019). Para hacer efectivo el traslado, consiguieron que la UNS le otorgase el cargo de Investigador Asociado para que trabaje la “estructuración social del área frutícola del Alto Valle del Rio Negro” y lo nombraron interino, con el cargo de "Profesor Asociado", en las materias "Teoría Económica Clásica I y II” (1972-1973). Luego vendrían los concursos, a partir de los cuales obtuvo

${ }^{22}$ Con la salvedad de un artículo publicado en 1972 en la Revista del Consejo Profesional de Ciencia Económicas de la Provincia de Córdoba (CIAFARDINI, 1972b). 
los cargos de "profesor de Microeconomía en el Curso Superior de Planificación Regional" del "Depto. De Economía", el de "Profesor Asociado ordinario" para desempeñarse en la materia "Economía Política III" que se dictaba en el Instituto Universitario de Olavarría y, finalmente, el de "Profesor Titular" en el "Área Teoría Económica II" para seguir desarrollando su tarea docente en las materias "Teoría Económica Clásica I y II". Al mismo tiempo, ganó un cargo de "Profesor Adjunto ordinario, por concurso nacional, de Macroeconomía" en la Universidad Nacional de Rio Cuarto, ciudad a la que viajaba una vez por semana para dar clases (CIAFARDINI, Curriculum Vitae, febrero de 1976).

En ese contexto, a raíz del vínculo que tenía el PCR con el grupo Pasado y Presente $^{23}$, tradujo y se publicaron, en el curso del año 1972, Teoría Económica del periodo de transición de Nikolai Bujarin e Introducción a la economía política de Rosa Luxemburg. La economía política marxista era, sin lugar a dudas, su gran preocupación. Por tal razón, seguía de cerca los debates que se producían alrededor del globo y trabajaba con temas candentes sobre fuentes que conocía en su lengua prima. En ese plano, publicó, junto con Carlos Cristiá y Roque Caggiano, En torno a la acumulación y el imperialismo (1974), que incluyó, entre otros trabajos, una crítica suya a la teoría de la realización de la plusvalía y la acumulación en Rosa Luxemburg.

En cuanto a su producción escrita, entre 1972 y 1973, publicó una serie de artículos y trabajos que, por su temática, podemos agrupar en dos grupos. Por un lado, están los trabajos que giraron en torno al problema del modo de producción dominante en América Latina como: México: la reforma agraria y los datos de 1960 (1972a), La reforma agraria mexicana (1972b), Sur la question du mode de production en Amérique Latine (1972d) y Capital, comercio y capitalismo: a propósito del llamado 'capitalismo comercial $^{24}$ (1973a). Además, publicó un folleto biográfico del mexicano Lázaro Cárdenas en la colección Historia e América en el siglo XX del CEAL (Ciafardini, 1972e). El trabajo, lejos de ser estrictamente una breve biografía, se inmiscuía en el proceso revolucionario y la reforma agraria, tema que Ciafardini había estudiado en profundidad en su tesis doctoral. Pese a esto, el contenido del mismo fue modificado

\footnotetext{
${ }^{23}$ Sobre esta relación, véase el artículo de Horacio Crespo (2009: 179-186)

${ }^{24}$ Este artículo, que aparecería en el mítico $\mathrm{n}^{\circ} 40$ de los Cuadernos de Pasado y Presente, según las referencias que aparecen en el trabajo publicado en francés, estaba inicialmente destinado para su publicación en la revista de la Universidad de Concepción, Economía y Administración (CIAFARDINI, 1972d: 148).
} 
por el director de la colección, Alberto $\mathrm{J}_{\text {. }} \mathrm{Pla}^{25}$, lo que lo motivó a manifestar sus quejas a la editorial. Frente a esto, José Luis Romero le planteó que lo único que podía ofrecer frente a su disconformidad era "suprimir su nombre [...] a partir del próximo número que vaya a la imprenta" (Carta de José Luis Romero a Horacio Ciafardini, Adrogué, 19/10/72. Archivo personal de María Inés Olivella). Luego, estipulamos que, en 1973, se publicó otro trabajo en la reabierta colección Nuevo Siglomundo. La historia temática del siglo $X X^{26}$, también del CEAL, titulado Economía y economistas del siglo XX donde presentó un panorama del desarrollo científico de la economía y los economistas, brindando un gran protagonismo a los aportes marxistas para comprender estos desarrollos (CIAFARDINI, S/F [1973]).

Por otro lado, perteneciente al segundo grupo, apareció Acumulación y centralización del capital en la industria argentina (1973). Este libro, producto de una elaboración colectiva con Eugenio Gastiazoro ${ }^{27}$ (con quien compartía la pertenencia al PCR), Elsa Cimilo, Edgardo Lifschitz y Mauricio Turkieh, buscó desentrañar el tipo de desarrollo capitalista que se desenvolvía en el país, polemizando con quienes lo equiparaban a "los países desarrollados". La editorial donde se publicó, Tiempo Contemporáneo seria de allí en más un lugar de trabajo. Entre 1973 y 1975, dirigió la colección Economía y Sociedad donde tradujo y publicó obras de suma transcendencia para la ciencia económica. Ellas fueron: El imperialismo y la acumulación de capital (1974) de Nikolai Bujarin; Valor y precio de producción (1975), donde se compiló una discusión en torno al tercer tomo de El Capital entre Eugen Böhm von Bawerk y Rudolf Hilferding; La oferta de la moneda (1975) de Suzanne Bruhoff; y también se dio lugar, a pesar de las discusiones, a que Oscar Braun publique una compilación titulada Teoría del capital y la distribución $(1973)^{28}$.

Entre fines de 1973 y principios de 1974, Horacio Ciafardini se asentó definitivamente en Buenos Aires. A pesar de tener la mayoría de su trabajo en Bahía Blanca -hacia donde viajaba todas las semanas para cumplir con sus tareas docentes y

\footnotetext{
${ }^{25}$ Destacado historiador rosarino de filiación trotskista.

${ }^{26}$ Esta colección inició su publicación en 1968, pero debió interrumpirse en 1969 por la prohibición realizada por el gobierno de Juan Carlos Onganía, hasta su nueva salida en 1973. El número 13, escrito por H. Ciafardini, no cuenta con fecha de publicación impresa y los catálogos tampoco proporcionan esa información (GOCIOL, 2007: 119-123)

${ }^{27}$ Sobre la trayectoria política e intelectual de Eugenio Gastiazoro véase: Rubio (2019)

${ }^{28}$ En ella hay trabajos de Alfredo Monza, Joan Robinson, Nicholas Kaldor, Luigi L. Pasinetti, Ronald L. Meek, Paul A, Samuelson, Robert M. Solow, Amit Bhaduri, G. C. Harcourt, Domenico Mario Nuti, Maurice Dobb y una introducción de Oscar Braun. H. Ciafardini tradujo del inglés el artículo de Paul A samuelson.
} 
donde se centralizaba políticamente-, ingresó a trabajar a la Universidad del Salvador (USAL) como Profesor Adjunto de Macroeconomía. Por otro lado, ingresó a la Universidad de Buenos Aires (UBA) impuesto por los estudiantes de la catedra de Economía Internacional que habían destituido a su titular por "apologista del sistema" 29 . Luego, fue designado como adjunto interino de Macroeconomía en la misma facultad (1973-1974) y en la Facultad de Derecho y Ciencias Sociales como "Profesor Adjunto de Economía Política”. Al mismo tiempo, la determinación de vivir en Buenos Aires pudo haber estado determinada por el creciente clima "tenso" que señalan algunos entrevistados respecto a lo que se estaba viviendo en la UNS, a partir del triunfo camporista.

Será a fines de 1974 cuando, a partir de la intervención de Alberto Eduardo Ottalagano, H. Ciafardini fue cesanteado de sus cargos docentes en la UBA, a pesar del apoyo estudiantil y la continuidad del dictado de clases por fuera de las estructuras formales de la institución ${ }^{30}$. Lo mismo ocurriría en la UNS, donde, a partir de la intervención Remus Tetu ${ }^{31}$, en 1974 comenzó a cesantearse docentes, perseguir al activismo estudiantil, planteando la eliminación de los contenidos que constituyeran una prédica contraria a la seguridad del país.

En este momento, de establecimiento en Buenos Aires, se produjo un fuerte desplazamiento político en su producción. Por un lado, comenzó a participar como un colaborador estable en la revista Los Libros -cuya dirección editorial, en los nombres de Beatriz Sarlo y Carlos Altamirano, se encontraba en manos del partido- ${ }^{32}$ y, por otro, actuó como el escriba que justificó en términos teóricos un viraje partidario de gran trascendencia que venía produciéndose desde $1974^{33}$. Con el seudónimo de Hugo Páez, justificó la nueva consideración sobre la burguesía nacional, el gobierno de Isabel Martínez de Perón y la posición “anti golpista” (CIAFARDINI, 1975c; 1975e; 1976b).

\footnotetext{
29 El titular desplazado aparece en un documento como "Gomariz". Comisión Homenaje Horacio Ciafardini, "Homenaje Horacio Ciafardini”, sin fecha (Mariposa que invita al acto de homenaje que se realizaría en la Facultad de Ciencias Económicas de la UBA), sin fecha.

${ }^{30}$ Diversos testimonios dan cuenta de que las clases de las materias continuaron a pesar de la intervención y el impedimento al desarrollo de su trabajo docente. A su vez, dan cuenta de la participación de Horacio Ciafardini de las distintas acciones desarrolladas por los estudiantes y docentes contra las cesantías y la intervención. Entrevistas a María Inés Olivella, realizadas por el autor entre noviembre de 2018 y abril de 2019. Entrevistas a Eugenio Gastiazoro, realizadas por el autor entre 2017 y 2019.

${ }^{31}$ Originario de Rumania, Bucarest, este personaje era un sociólogo sin título que había trabajado con anterioridad a la asunción del tercer gobierno peronista en la UNS. Volvió a desembarcar en la unidad académica de Bahía Blanca con la "misión Ivanissevich” y se encargó de llevar adelante, junto con los servicios de inteligencia y fuerzas paramilitares, la represión al movimiento estudiantil y los académicos.

${ }^{32} \mathrm{Al}$ respecto véase: Ciafardini (1973b; 1974c; 1974d; 1974e; 1975b).

${ }^{33} \mathrm{Al}$ respecto véase (RUBIO, 2018c).
} 
A su vez, comenzó a relacionarse con el Centro de Investigaciones en Ciencias Sociales (CICSO) dictando cursos y brindando sus trabajos para que se editaran en formato de cuadernillos. En ellos, encontramos, además de escritos que irían apareciendo en revistas y libros (CIAFARDINI, 1973c; 1973d), una línea de investigación asociada a su incumbencia en las cátedras universitarias: un análisis crítico de la economía clásica (CIAFARDINI, 1974a; 1975a), desde el marxismo. Por otro lado, los primeros avances en una obra de largo aliento que no pudo concluir destinada al abordaje de la caída de la tasa de ganancia en Marx (CIAFARDINI, 1974b).

$\mathrm{Al}$ encontrarse desplazado de sus cargos ordinarios en las universidades, Horacio Ciafardini logra ingresar al Consejo Federal de Inversiones (CFI) en carácter de personal técnico contratado, como asesor de un grupo de investigación, en enero de 1975, “para investigaciones en el ámbito de las cuencas de los ríos Pasaje - Juramento Salado y Salí-Dulce" (CIAFARDINI, Curriculum Vitae, febrero de 1976). Juan Iñigo Carrera, quien en ese momento compartía lugar de trabajo con él, lo recuerda como un personaje "solitario y siempre trabajando, que no se relacionaba con nadie, encerrado en lo suyo" (Entrevista a Juan Iñigo Carrera, realizada por el autor en octubre de 2019). El año y medio restante de libertad es sumamente enigmático en cuanto a su producción intelectual y actividad política; no se conocen más escritos que los aparecidos en la revista teórica del PCR.

\section{6-1984: la cárcel y la reinserción trunca}

H. Ciafardini fue detenido el 21 de julio de 1976 en el CFI por policías de civil, simultáneamente un operativo de la Policía Federal allanó su domicilio en el barrio porteño de Balvanera, casi San Cristóbal. El despojo fue total, de sus libros, apuntes, originales y documentación personal no quedó nada; incluso, recordó su mujer que, los peritos debieron contratar traductores del alemán, el ruso y el polaco para poder desentrañar la naturaleza de muchos de los papeles encontrados en el departamento de la calle Rincón, casi independencia.

A disposición del Poder Ejecutivo Nacional (PEN), Horacio fue privado de su libertad hasta el 16 de octubre de 1982: pasó, aproximadamente, dos meses en Bahía Blanca, cuatro años y ocho meses en Rawson y un año y cinco meses en La Plata. Sus 
amigos y familiares intentaron defenderlo, desde un primer momento, presentando sus escritos como la evidencia del trabajo de un profesional. En ese contexto, en septiembre de 1977, se publicó un libro que H. Ciafardini había compilado y prologado para la Biblioteca Total del CEAL, titulado La economía política clásica - Adam Smith, David Ricardo, François Quesnay, que intentó reforzar la hipótesis de la defensa ${ }^{34}$. Sin embargo, la justicia desestimó los reclamos.

En Rawson, compartió pabellón con presos políticos, donde todos los internos, inicialmente, tenían una celda individual, sin acceso a información externa y padecían las consecuencias de una política dirigida a aislarlos totalmente del mundo exterior. Una vez en libertad, los años 1978 y 1979 fueron recordados por H. Ciafardini como los peores: no se les permitió leer otra cosa que no fueran la biblia ${ }^{35}$, "libro hermoso, pero cuando uno lo ha leído cuatro o cinco veces entero se torna un poco monótono", y "otras lecturas, desde luego muy censuradas y volcadas al material intrascendente, superficial. El libro típico permitido era el 'best seller",36. Salvo por la lectura a escondidas de las hojas sueltas de diario destinadas a la higiene personal de los internos, les fue vedado el acceso a cualquier material referido a la actualidad. Por tal motivo, su mujer recuerda que estudiaba minuciosamente todos los periódicos para poder presentarle un panorama general de lo que era la situación política en cada visita al penal. En su cautiverio Horacio Ciafardini dictó cursos de idiomas y de economía política, particularmente de El Capital, a sus compañeros de pabellón. Un recuerdo colectivo, en el que coinciden varias personas que lo conocieron, relata que a determinada hora pactada los reclusos tiraban la cadena del inodoro desagotando la cañería que unía cada una de las celdas y, una vez habilitada esta vía de comunicación, el economista rosarino disertaba a viva voz sobre determinados temas y problemas

\footnotetext{
${ }^{34}$ En aquel momento, la situación legal de Ciafardini se discutió en el CEAL, del que Beatriz Sarlo y Carlos Altamirano formaban parte, como puede observarse en te fragmento: "[Beatriz Sarlo:] Entre los libros que nosotros habíamos encargado estaba la antología de economistas clásicos preparada por Horacio Ciafardini. Meses después de entregar el libro, Ciafardini cae preso. Le decimos entonces a Spivacow: 'Bueno, Boris, hay un problema...' Él nos mira -como si literalmente no entendiera- y nos contesta: 'Nosotros ese libro lo tenemos pautado y lo sacamos'. Después, se queda suspendido un momento y dice: ‘UUstedes piensan que lo puede perjudicar a Ciafardini?' [...] [Carlos Altamirano:] Hablen con los abogados de Ciafardini', nos dijo y ellos dijeron que al autor le convenía porque era parte de su defensa que él se especializaba en la enseñanza de clásicos de la economía política. 'Pero la introducción es de un marxista', insistí ante Boris. "Ah, chiquito, el Centro Editor nunca censura"" (GOCIOL, 2007: 217). La introducción finalmente fue firmada por Antonio Passano y la selección adjudicada a H. Ciafardini.

${ }^{35} \mathrm{Su}$ mujer recuerda que pudieron hacerle llegar una Biblia, propiedad de la familia, muy completa, con estudio introductorio y muchas ilustraciones y mapas.

36 "Los militares deben pasar su arresto trabajando", Nueva Presencia, n 376, 14/09/84, pp. 9-12.
} 
pactados con anterioridad con sus compañeros (Entrevista a Maria Ines Olivella, Comunicación personal con Gabriel Levinas en marzo de 2019).

Durante este período en el sur, una tía, que era madrina de un secretario del presidente de facto Jorge Rafael Videla, consiguió el salvoconducto para que pueda abandonar el país, a condición de que reconozca su responsabilidad en la "infiltración ideológica contra la nación”, pero este se negó a aceptarlo. Al respecto sostuvo que no era "cuestión de salir como rata por tirante", sino que se trataba de intentar "desentrañar la patraña jurídica de connivencia con la dictadura", insistiendo en lo "científico de su trabajo" (Entrevista Maria Ines Olivella, realizadas por el autor entre diciembre de 2018 y abril de 2019; MARTÍNEZ, 2005). Esta actitud estaba totalmente ligada a la directiva del partido respecto a que los militantes debían quedarse en el país para combatir a la dictadura $^{37}$. Lo mismo ocurrió con su comportamiento: salvo los cigarrillos, rechazó gastar su dinero en comprar comida que vendían los guardias como negocio, lo que le valió el apodo de “Asceta". Recién en 1980-81, en la ciudad de La Plata, logró tener acceso regular a publicaciones periódicas: a través de las cuales siguió con gran expectativa la guerra de Malvinas. Mientras tanto, durante todo este período sus antiguos colegas realizaban colectas de dinero por diversos rincones del globo, para solventar la manutención y los viajes de sus familiares a los penales, especialmente a Rawson $^{38}$. Por otra parte, muchos de sus colegas realizaron una campaña internacional por su libertad. Ejemplo de ello es la carta que envió el presidente del Comité de Derechos Humanos de la Academia Nacional de Ciencias de EE. UU. al presidente argentino Reynaldo Bignone pidiéndole información respecto a su estado procesal y solicitando una dirección donde enviarle correspondencia. ${ }^{39}$

En octubre de 1982 Ciafardini salió de la cárcel bajo el régimen de libertad vigilada, condición que duraría hasta agosto de 1983, mientras el gobierno militar se derrumbaba $^{40}$. A partir de allí comenzó su tortuoso camino de reinserción laboral. Lo

\footnotetext{
37 Miguel Rubinich, destacado militante de la regional Santa Fe del PCR, dice al respecto en sus memorias que "durante la dictadura cavamos una trinchera y nos quedamos en el país, decidido por el Comité Central. Rechazamos incluso la posibilidad que daban estando presos de irnos del país, nos negábamos a eso y si algún compañero lo aceptaba era sancionado (...). Por esa resolución tuvimos compañeros presos durante muchos años" (RUBINICH, 2011: 68)

${ }^{38}$ Una carta del Archivo personal de José Carlos Chiaramonte da cuenta de tal situación: colecta y envío de dinero desde México y explicación de parte de la familia de su incapacidad económica de solventar los gastos para ir a visitarlo. Carta de Eduardo Ciafardini a José Carlos Chiaramonte, Rosario, 10/01/81. Archivo personal de José Carlos Chiaramonte.

${ }^{39}$ State Argentina Declassification Project (1975-1984), U.S. Department of State, 21/01/83.

40 A pesar de los plazos formales de su situación procesal, hay muestras de cierta desconfianza de $\mathrm{H}$. Ciafardini respecto a la privacidad de su correspondencia en los últimos dos años de su vida. Durante este
} 
primero que consiguió para subsistir fue una beca del Consejo Latinoamericano de Ciencias Sociales (CLACSO) destinada a concluir una obra que había comenzado a escribir antes de su encarcelamiento, a la que tituló El valor en la concurrencia. El libro en cuestión iba a ser publicado originalmente por la entidad que financió la investigación, pero esto no se producía: "la cosa es lenta, demasiado lenta para confiar en que, por esa vía, el producto llegue fresco al mercado", le escribió a José Carlos Chiaramonte que se encontraba en México y le solicitó que explorara la posibilidad de ofrecerlo allí. Durante su último año de vida Ciafardini intentó que saliera a la luz la edición en español del libro, mientras tanto lo difundió por el mundo académico europeo y norteamericano, con el que tenía contacto asiduo antes de estar detenido, entre los que se encontraban Charles Bettelheim, Edmond Malinvaud y Paul M. Sweezy. Sin embargo, su intención era que la publicación en español tenga inmediatamente sus réplicas en "algunos de los idiomas en los que la polémica sobre la teoría del valor se desenvuelve predominantemente" (Carta de Horacio Ciafardini a José Carlos Chiaramonte, Buenos Aires, 27/10/83. Archivo personal de José Carlos Chiaramonte). En México fue ofrecido a FCE y a Grijalbo, que lo rechazaron con argumentos similares: una supuesta especificidad temática que restringía al posible público lector y un desencuentro con los propósitos de las colecciones existentes (Carta de Rogelio Carabajal (Grijalbo) a José Carlos Chiaramonte, México D. F., 01/02/84; Carta de Rogelio Carabajal (Grijalbo) a José Carlos Chiaramonte, México D. F., 28/02/84; Carta de Socorro Cano (FCE) a José Carlos Chiaramonte, México D. F., 23/01/85. Archivo personal de José Carlos Chiaramonte). Una vez que Horacio C. había fallecido, su mujer aseguraba haber conseguido que lo publicara el CEAL "con introducción de Charles Bettelheim, Paul Sweezy, E. Milinvaud [...] para mediados de año [1985]" (Carta de María Inés Olivella a José Carlos Chiaramonte, Buenos Aires, 25/03/85. Archivo personal de José Carlos Chiaramonte). Pese a las gestiones, el libro no vería la luz hasta el año 2004, cuando se publicaron algunos de sus escritos por iniciativa de Carlos Cristiá, Edgardo Ferrer y sus amigos rosarinos (CIAFARDINI, 2004: 6).

período, ante la vigilancia constante de que sospechaba ser objeto, pidió a sus remitentes que dirigieran sus cartas a otras direcciones, no a su domicilio legal. Por ejemplo, a José Carlos Chiaramonte le solicitó, en octubre de 1983, "Por razones de seguridad postal, te ruego me escribas como lo indico más arriba, al pie de la letra: a casa de mi cuñado y poniendo el sobre sólo a nombre de él, vale decir sin indicar mi nombre en el sobre". Carta de Horacio Ciafardini a José Carlos Chiaramonte, Buenos Aires, 27/10/83. Archivo personal de José Carlos Chiaramonte. 
Con el retorno a la democracia, Horacio Ciafardini emprendió la lucha por la devolución de su cargo docente en la UBA. Para ello, formó parte de una comisión de docentes cesanteados, junto con organizaciones estudiantiles, que reclamó por la restitución de las cátedras y la realización de nuevos concursos democráticos mediante una campaña de constó de actos y junta de firmas a personalidades públicas. De aquella batalla Horacio conquistaría una victoria parcial: le restituyeron su cargo de Profesor Asociado en Macroeconomía de la Facultad de Ciencias Económicas, pero solamente para el desarrollo de tareas de investigación y no de docencia, como deseaba.

Durante los primeros meses de 1984 publicó una serie de artículos en la revista El Porteño, dirigida por Gabriel Levinas. El acercamiento a la publicación se habría producido a raíz de una nota que preparaban los editores sobre las cárceles durante la dictadura, para la cual lo habrían entrevistado. Esta invitación al desarrollo de un trabajo remunerado, fue facilitada por el hecho de que en el período previo al golpe habían compartido la militancia en el PCR y Levinas conocía su delicada situación económica (Comunicación personal con Gabriel Levinas en marzo de 2019). De esta manera, se publicaron cuatro artículos que salieron desde enero hasta abril, inaugurando una efímera sección de economía, donde Horacio Ciafardini se centró en la explicación del fenómeno inflacionario y la deuda externa (CIAFARDINI, 1984a; 1984b; 1984c; 1984d).

En este periodo, hay un gris respecto a su pertenencia orgánica al PCR. Por un lado, su mujer sostuvo que Horacio se habría alejado de la militancia una vez que se encontró en libertad y luego de producirse una serie de debates en su domicilio con miembros del Comité Central que prefirió no especificar. Por otro, compañeros de militancia sostienen que esto habría ocurrido solamente como una pantalla frente a sus problemas personales y que el contacto había seguido siendo asiduo y cordial, más allá de algunas discusiones en torno a la naturaleza del gobierno alfonsinista. Esto último, es reforzado por la aparición de dos trabajos suyos en revistas relacionadas al partido, aunque en ambos casos con seudónimo. En 1981, en Teoría y Política, se publicó un artículo suyo sobre El Capital y, en 1983, en la revista Síntomas, editada por intelectuales vinculados al PCR, otro sobre la teoría económica marxista (CIAFARDINI, 1981; 1983).

Lo cierto es que, en 1984, sostuvo, en una entrevista sobre su estadía en la cárcel, "comparto todas las ideas en cuestión y sigo pensando que los planteos del PCR en aquella época fueron enteramente justos [coyuntura 1974-1976]; incluso los de hoy”. 
Sin embargo, inmediatamente después, a partir de una pregunta respecto al carácter "socialimperialista" del gobierno de Salvador Allende, este se excusa y plantea que no puede "hablar en nombre del PCR ni del PTP; simplemente, comparto sus planteos, pero no puedo de ninguna manera hablar en nombre de ninguno de esos partidos. Actualmente no actúo en política" ${ }^{\natural 1}$.

El 15 de octubre de 1984, la vida de Horacio Ciafardini terminó abruptamente. Meses antes había producido dos textos que, a diferencia de los anteriores, se ocuparon frontalmente con la situación política y económica argentina. En junio de 1984 había concluido la redacción de un artículo en francés, cuyo título en español fue Argentina 1976-1983: La estrategia de desindustrialización de la dictadura, en septiembre había pronunciado una conferencia en el Instituto Rosarino de Estudios Sicosocial (IRDES), cuya desgravación fue titulada La Argentina en el mercado mundial contemporáneo, y en octubre había participado en las XIV Jornadas Nacionales de Economía, con una ponencia titulada Inflación y política antiinflacionaria (el empleo, la magnitud y la distribución del ingreso y el desarrollo en un marco inflacionario) (CIAFARDINI, 1990). En este sentido, consideramos que H. Ciafardini estaba experimentando un nuevo vuelco en su producción: sobrepasando, pero no abandonando, la economía teórica en dirección a una inquietud coyuntural, frente a una realidad profundamente transformada durante su cautiverio que debía comprender.

\section{A modo de cierre}

A lo largo de este trabajo hemos analizado la trayectoria política e intelectual de Horacio Ciafardini. Observada de conjunto, advertimos en ella una preminencia de los espacios académicos y profesionales en el despliegue de sus producciones y conocimientos, pese a su presencia, siempre bajo seudónimo, en el ámbito político y, fundamentalmente, partidario. Sin embargo, consideramos que su vida y obra deben ser pensadas en el punto de intersección de esos dos ámbitos y no en su supuesta división: los límites, en este caso, se encuentran sumamente difusos y demarcarlos, para fragmentar el análisis, constituiría un obstáculo en la comprensión general. Haciendo uso de esta perspectiva general, que comprendió todo el desarrollo de su vida (19421984), hemos podido identificar una serie de momentos, expresados en los subtítulos, y,

41 "Los militares deben pasar su arresto trabajando", Nueva Presencia, n 376, 14/09/84, pp. 9-12. 
sobre todo, de problemas que reclaman ser profundizados. Por otro lado, también hemos delimitado los temas que fueron predominantes en su producción en determinados momentos y sus líneas de investigación perdurables en el tiempo.

En tanto sistematización, consideramos que este escrito se constituye como un punto de partida para futuros trabajos y, como tal, permite avanzar en el abordaje de, al menos, dos núcleos problemáticos centrales y otros tantos derivados. Por un lado, en cuanto a su trayectoria, la necesidad de identificar, con mayor precisión, los momentos de ruptura, vuelco, imposición o toma de decisión en busca de los factores que intervinieron dando un curso particular a esta. Por otro, se pone de manifiesto la importancia de analizar la relación, vinculo y/o contradicción, de la obra de Horacio Ciafardini con las ideas y planteos desarrollados, en las distintas coyunturas, por la organización a la que perteneció. En este punto, consideramos que se trató de una relación dinámica, y poder identificar y analizar esos momentos será clave para pensar la relación intelectual-partido en un período particularmente conflictivo de la Historia Argentina. En ese plano más general, remarcamos la vacancia de estudios sistemáticos en torno a la cuestión intelectual, particularmente del campo de la izquierda marxista, entre las décadas de los '60 y '80 del siglo pasado; tarea a la que esperamos, modestamente, contribuir.

\section{Fuentes}

Trabajos de Horacio Ciafardini:

\section{Artículos y libros}

BARSKY, Osvaldo; CIAFARDINI, Horacio; Cristiá, Carlos Alberto (1971). Producción y tecnología en la región pampeana, Polémica CEAL. Buenos Aires, $\mathrm{n}^{\circ} 55$.

CIAFARDINI, Horacio (1970). Algunas deficiencias de la planificación en la práctica de los países socialistas". Economía y Administración. Universidad de Concepción - Chile, ${ }^{\circ}$ 14, primer cuatrimestre de 1970, pp. 27-35.

CIAFARDINI, Horacio; Cristiá, Carlos Alberto (1971). La explotación imperialista y el 'comercio exterior'. Rosario: Centro de Trabajadores Intelectuales.

CIAFARDINI, Horacio et al. (1971). Dependencia, integración y monopolios en América Latina. Rosario: Centro de Trabajadores Intelectuales.

CIAFARDINI, Horacio (1971a). 'Capitalismo comercial': ¿concepto científico?. Rosario: Centro de Trabajadores Intelectuales.

CIAFARDINI, Horacio (1971b). La Revolución Mexicana y el desarrollo capitalista de la agricultura. Rosario: Centro de Trabajadores Intelectuales. 
CIAFARDINI, Horacio (1971c). Concepciones 'tercermundistas' en la teoría de las relaciones económicas internacionales. Economía y Administración. Universidad de Concepción - Chile, $\mathrm{n}^{\circ}$ 19-20, tercer cuatrimestre de 1971, s/p.

CIAFARDINI, Horacio [Páez, Héctor] (1971d). Bibliográfica: Desarrollo del capital monopolista en Argentina de Oscar Braun (Bs. As., Tiempo Contemporáneo, 1970). Teoría y Política. Buenos Aires, ${ }^{\circ} 5$, mayo-junio, pp. 37-43.

CIAFARDINI, Horacio [Páez, Hugo] (1971e). Bibliográfica: La dependencia político económica de América Latina de H. Jaguaribe, A. Ferrer, M. S. Wionezek y Th. Dos Santos (Siglo XXI, 1969). Teoría y Política. Buenos Aires, $\mathrm{n}^{\circ}$ 5, mayo-junio de 1971, pp. 45-52.

CIAFARDINI, Horacio [Páez, Hugo] (1971f). Bibliográfica: El tratado de economía marxista de Ernest Mandel. Teoría y Política. Buenos Aires, $\mathrm{n}^{\circ} 7$, noviembre diciembre de 1971, pp. 79-86.

CIAFARDINI, Horacio (1972a). México: la reforma agraria y los datos de 1960. Desarrollo Económico. Buenos Aires, n47, abril - junio de 1972, Buenos Aires, pp. 81-103.

CIAFARDINI, Horacio (1972b). La reforma agraria mexicana. Problemas del Desarrollo - Revista Latinoamericana de Economía, México D. F., $\mathrm{n}^{\circ} 11$, de enero a abril de 1972, pp. 53-76.

CIAFARDINI, Horacio; Cristiá, Carlos Alberto (1972). Estudio de campo y elaboración de las cuentas sociales de Casilda para 1969. Metodología y principales resultados. Desarrollo Económico. Buenos Aires Instituto de Desarrollo Económico y Social. n ${ }^{\circ}$ 47, vol. 12, octubre-diciembre de 1972, pp. 565-580.

CIAFARDINI, Horacio (1972c). El funcionamiento del sistema de precios en una economía socialista. Ciencias Económicas - Revista del Consejo Profesional de Ciencia Económicas de la Provincia de Córdoba. Córdoba, nº 6, 1972, Córdoba, pp. 9-31.

CIAFARDINI, Horacio (1972d). Sur la question du mode de production en Amérique Latine. études rurales. ÉCOLE PRACTIQUE DES HAUTES ÉUDES SORBONNE, París n 47, 1972, pp. 148-162.

CIAFARDINI, Horacio (1972e). Cárdenas: la Revolución Mexicana, Historia de América Latina. Buenos Aires: Centro Editor de América Latina.

CIAFARDINI, Horacio [Páez, Hugo] (1972f). Bibliográfica: El problema del intercambio desigual, Arghiri Emannuel. Teoría y Política. Buenos Aires, $\mathrm{n}^{\circ} 8$, marzo - abril de 1972, pp. 23-29.

CIAFARDINI, Horacio [Páez, Hugo] (1972g), "VARSAVSKY: PROYECTOS NACIONALES" [bibliográfica], Los Libros, n 27, julio de 1972, pp. 27-28.

CIAFARDINI, Horacio; CIMILO, Elsa; LIFSCHITZ, Edgardo; GASTIAZORO, Eugenio; TURKIEH, Mauricio (1973). Acumulación y centralización del capital en la industria argentina. Buenos Aires: Tiempo Contemporáneo.

CIAFARDINI, Horacio (S/F [1973]). Economía y economistas del siglo XX. Buenos Aires: CEAL.

CIAFARDINI, Horacio (1973a). Capital, comercio y capitalismo: a propósito del llamado 'capitalismo comercial'. VV. AA., Modos de producción en América Latina, Cuadernos de Pasado y Presente. Córdoba, n 40, 1973, pp. 111-134.

CIAFARDINI, Horacio (1973b). Argentina: desarrollo capitalista dependiente y discurso ideológico. Los Libros. Buenos Aires, n ${ }^{\circ}$ 29, marzo-abril 1973, pp. 1519. 
CIAFARDINI, Horacio (1973c). 'Concepciones 'tercermundistas' en la teoría de las relaciones económicas internacionales. Buenos Aires: CICSO - serie polémica $\left(\mathrm{n}^{\circ} 2\right)$.

CIAFARDINI, Horacio (1973d). Sobre el problema de la realización de la plusvalía y la acumulación de capital (Intento de crítica de la teoría de Rosa Luxemburgo. Buenos Aires: CICSO - SERIE ANALISIS NUMERO 1.

CIAFARDINI, Horacio; CRISTIA, Carlos; CAGGIANO, Carlos (1974). En torno a la Acumulación y al Imperialismo. Rosario: Encuadre.

CIAFARDINI, Horacio (1974a). Trabajo asalariado, capital y valor de cambio (Análisis de la teoría de Adam Smith sobre el valor de cambio). Buenos Aires: CICSO.

CIAFARDINI, Horacio (1974b). La caída de la tasa de ganancia. Buenos Aires: CICSO - serie análisis $\mathrm{n}^{\circ} 7$.

CIAFARDINI, Horacio (1974c). Economía: liberación y dependencia. Los Libros. Buenos Aires, $\mathrm{n}^{\circ}$ 33, enero - febrero 1974, pp. 15-16.

CIAFARDINI, Horacio (1974d). Revolución cultural, revolución en la producción. Los Libros. Buenos Aires, $\mathrm{n}^{\circ}$ 35, mayo - junio de 1974, pp. 10-13.

CIAFARDINI, Horacio (1974e). Feudalismo: economía y sociedad. Los Libros. Buenos Aires, $\mathrm{n}^{\circ}$ 37, septiembre - octubre de 1974, Buenos Aires, pp. 20-23.

CIAFARDINI, Horacio (1975a). David Ricardo: valor y capital. Buenos Aires: CICSO - serie análisis $\mathrm{n}^{\circ} 3$.

CIAFARDINI, Horacio (1975b). U.R.S.S. ¿Capitalismo o socialismo?”. Los Libros. Buenos Aires, $n^{\circ}$ 39, enero - febrero de 1975, Buenos Aires, pp. 24-26.

CIAFARDINI, Horacio [Hugo Páez] (1975c). ¿Por qué la crisis no se resuelve sin revolución?. Teoría y Política. Buenos Aires, ${ }^{\circ}$ 15, agosto de 1975, pp. 25-28

CIAFARDINI, Horacio [Hugo Páez] (1975e), Critica de la teoría del capitalismo dependiente. Teoría y Política. Buenos Aires, n 16, noviembre de 1975, pp. 1422.

CIAFARDINI, Horacio (1976a). Economía y economistas del siglo XX, Nuevo Siglomundo - La Historia temática del siglo XX, $n^{\circ}$ 63. Buenos Aires: Centro Editor de América Latina.

CIAFARDINI, Horacio [Hugo Páez] (1976b). Sobre algunos enfoques unilaterales en historia". Teoría y Política. Buenos Aires, n 17, marzo de 1976, pp. 20-22.

CIAFARDINI, Horacio (1977). La economía política clásica. Smith, Ricardo, Quesnay (Selección de textos, traducción e introducción). Buenos Aires: Centro Editor de América Latina.

CIAFARDINI, Horacio [Camilo Paz] (1981). Sobre 'El Capital'. Teoría y Política. Buenos Aires, $\mathrm{n}^{\circ}$ 29, julio de 1981, pp. 37-41.

CIAFARDINI, Horacio [Hugo Páez] (1983). Sobre la teoría económica de Marx, a cien años de su muerte. Síntomas. Buenos Aires, n 6, 1983, pp. 36-41.

CIAFARDINI, Horacio (1984a). Qué es esto de la inflación. El Porteño. Buenos Aires, $\mathrm{n}^{\circ} 25$, enero de 1984, pp. 32-34.

CIAFARDINI, Horacio (1984b). Dinero verdadero, 'dinero falso' e inflación. El Porteño. Buenos Aires, ${ }^{\circ}$ 26, febrero de 1984, pp. 44-45.

CIAFARDINI, Horacio (1984c). "Cómo se origina la inflación y cómo librarse de ella". El Porteño. Buenos Aires, n 27, marzo de 1984, pp. 39-71.

CIAFARDINI, Horacio (1984d). ¿De dónde sale la deuda externa?. El Porteño. Buenos Aires, $\mathrm{n}^{\circ} 28$, abril de 1984, pp. 88-89.

CIAFARDINI, Horacio (1984e). Acerca del modelo de Amin y la proporción entre los factores. Inédito. 
CIAFARDINI, Horacio (1990). Crisis, inflación y desindustrialización en la Argentina dependiente. Buenos Aires: Ágora. [Contiene: Argentina 1976-1983: La estrategia de desindustrialización de la dictadura (original en francés, junio de 1984); La Argentina en el mercado mundial contemporáneo (Inédito, desgravación de conferencias pronunciadas en el IRDES de Rosario en septiembre de 1984) e; Inflación y política antiinflacionaria (el empleo, la magnitud y la distribución del ingreso y el desarrollo en un marco inflacionario (trabajo presentado a las XIV Jornadas Nacionales de Economía, Rosario, octubre de 1984)]

CIAFARDINI, Horacio (2002). Textos sobre economía política e historia (Selección de trabajos). Rosario: Amealevi.

CIAFARDINI, Horacio (2003). Sobre las teorías de las crisis económicas. Rosario: Amealevi.

CIAFARDINI, Horacio (2004). El valor en la concurrencia [1984]. Rosario: Amealevi.

\section{Traducción y edición}

1972, dos traducciones para Pasado y Presente:

BUJARIN, Nicolai I. (1972). Teoría Económica del periodo de transición. Buenos Aires: Pasado y Presente.

LUXEMBURG, Rosa (1972). Introducción a la economía política. Buenos Aires: Pasado y Presente.

1973-1975, Director de la colección Economía y Sociedad de la editorial Tiempo Contemporáneo, donde se desempeñó como traductor y editor:

BRAUN, Oscar; Maurice DOBB y otros (1973). Teoría del capital y la distribución. Buenos Aires: Tiempo Contemporáneo.

BUJARIN, N. (1974). El imperialismo y la acumulación de capital. Buenos Aires: Tiempo Contemporáneo.

BOHM-BAWERK, E. Von y HILFERDING, R. (1975). Valor y precio de producción. Buenos Aires: Tiempo Contemporáneo.

BRUHOFF, Suzanne (1975). La oferta de la moneda. Buenos Aires: Tiempo Contemporáneo.

\section{Testimonios:}

\section{Inéditos}

Comunicación personal con Miguel Angel Ferrari, septiembre de 2019.

Comunicación personal con Gabriel Levinas, marzo de 2019.

Entrevista a Juan Iñigo Carrera, realizada por el autor en octubre de 2019.

Entrevista a Edgardo Ferrer, realizada por el autor en septiembre de 2019.

Entrevistas a Osvaldo Barsky, realizadas por el autor en julio y agosto de 2019.

Entrevistas a Maria Ines Olivella, realizadas por el autor entre diciembre de 2018 y abril de 2019.

Entrevista a Aldo Mangiaterra, realizada por el autor en septiembre de 2019.

Entrevista a Carlos Altamirano, realizada por el autor en octubre de 2019.

Entrevista a José Carlos Chiaramonte, realizada por el autor en marzo de 2019.

Entrevistas a Eugenio Gastiazoro, realizadas por el autor entre 2017 y 2019.

\section{Editados}


"Los militares deben pasar su arresto trabajando". Nueva Presencia, n 376, 14/09/84, pp. 9-12.

Aldo Mangiaterra, "50 años de la Primavera de Praga" en: https://aldomangiaterra.blogspot.com/2018/08/a-50-anos-de-la-primavera-depraga.html

BARSKY, Osvaldo (2018). Ciencias sociales. Pasión por los libros. Ciencia $e$ Investigación Reseñas. Buenos Aires, tomo 6, n 4, 2018, UNSam, pp. 26-44.

GOCIOL, Judith (2007). Más libros para más: colecciones del Centro Editor de América Latina. Buenos Aires: Biblioteca Nacional.

MARTÍNEZ, Diego (2005). "De cómo Madueño "limpió” la facultad de "subversivos"”, Pagina 12, 30 de mayo. Disponible en: https://www.pagina12.com.ar/diario/elpais/1-51714-2005-05-30.html [consultado en octubre de 2019]

RUBINICH, Miguel (2011). Apuntes sobre la historia del Regional Santa Fe. Partido Comunista Revolucionario. Rosario: Librería Social Universitaria.

SALVATORE, Sergio (1985). Homenaje a Horacio Ciafardini. Nudos. Buenos Aires, $\mathrm{n}^{\circ}$ 15,15 de octubre de 1985, pp. 22-24.

\section{Listado de archivos consultados y fuentes}

E.E.M N 432 "Bernardiño Rivadavia", donde anteriormente funcionó el "Liceo Nacional de Señoritas Bernardino Rivadavia": Legajo de Horacio Ciafardini, E.E.M Nº 432 "Bernardiño Rivadavia", 1961-1964.

Archivo personal de María Inés Olivella: "Breve reseña sobre mi carrera", Horacio Ciafardini, s/f.; Comisión Homenaje Horacio Ciafardini, "Homenaje Horacio Ciafardini", (Mariposa que invita al acto de homenaje que se realizaría en la Facultad de Ciencias Económicas de la UBA), sin fecha; Horacio Ciafardini, Curriculum Vitae, Buenos Aires, febrero de 1976; Carta de José Luis Romero a Horacio Ciafardini, Adrogué, 19/10/72;

Archivo personal de José Carlos Chiaramonte: Carta de Eduardo Ciafardini a José Carlos Chiaramonte, Rosario, 10/01/81; Carta de Horacio Ciafardini a José Carlos Chiaramonte, Buenos Aires, 27/10/83; Carta de Horacio Ciafardini a José Carlos Chiaramonte, Buenos Aires, 27/10/83; Carta de Rogelio Carabajal (Grijalbo) a José Carlos Chiaramonte, México D. F., 01/02/84; Carta de Rogelio Carabajal (Grijalbo) a José Carlos Chiaramonte, México D. F., 28/02/84; Carta de Socorro Cano (FCE) a José Carlos Chiaramonte, México D. F., 23/01/85; Carta de María Inés Olivella a José Carlos Chiaramonte, Buenos Aires, 25/03/85.

State Argentina Declassification Project (1975-1984), U.S. Department of State, 21/01/83.

\section{Referencias bibliográficas}

CALIFA, Juan Sebastian (2015). Del Partido Comunista al Partido Comunista Comité Nacional de Recuperación Revolucionaria en la Argentina de los años sesenta. Una escisión con marca universitaria. Izquierdas. $\mathrm{n}^{\circ} 24$, julio 2015, IDEAUSACH, pp. 173-204

CAMPIONE, Daniel (2008). La izquierda no armada en los años setenta: tres casos, 1973-1976. En LIDA Clara E., CRESPO Horacio y YANKELEVICH Pablo 
(compiladores). Argentina 1976. Estudios en torno al golpe de Estado. Buenos Aires, FCE, pp. 85-110.

CISILINO, Juan Manuel (2017). Debates sobre el camino de la revolución en los orígenes del Partido Comunista Revolucionario (1967-1969). Ponencia presentada en las XVI Jornadas Interescuelas/ Departamentos de Historia, realizada los días 9, 10 y 11 de agosto de 2017 en la ciudad de Mar del Plata, Provincia de Buenos Aires.

DI PASQUALE, Mariano y SUMMO, Marcelo (2015). Trayectorias singulares, voces plurales. Intelectuales en la argentina siglos XIX-XX. Buenos Aires: EDUNTREF.

GILBERT, Isidoro (2009). El PCR surgió de las entrañas de la FJC. En: GILBERT, Isidoro. La FEDE. Alistándose para la revolución. La Federación Juvenil Comunista 1921-2005. Buenos Aires, Sudamericana, pp. 520-550.

LISSANDRELLO, Guido (2015). La discusión estratégica en la izquierda argentina en los años 70. Aproximación al debate entre guerrillerismo e insurreccionalismo en el nacimiento del Partido Comunista Revolucionario (PCR), 1967-1972. ANDES. Salta, S/P.

(2018). El maoísmo argentino frente a la cuestión agraria en los '70: el caso de Vanguardia Comunista y el Partido Comunista Revolucionario (1969-1976). Tesis de Licenciatura en Historia, FILO-UBA.

RUBIO, Matias (2017). Estrategia e inserción del Partido Comunista Revolucionario en el SMATA (1979-1985). Archivos de historia del movimiento obrero y la izquierda (ISSN 23139749). Buenos Aires, año VI, no 11, septiembre de 2017, pp. 143-162.

- (2018a). El Partido Comunista Revolucionario y la construcción de una interpretación histórico-política en torno a la cuestión agraria (19671987). Conflicto Social (ISSN 1852-2262). Vol. 11, N²0, julio a diciembre 2018, pp. 61-91.

(2018b). El Partido Comunista Revolucionario y la definición de una interpretación histórica en su período formativo (1967-1987). Izquierdas (ISSN 0718-5049). $\mathrm{N}^{\circ} 46$, agosto 2018, pp. 137-161.

(2018c). El Partido Comunista Revolucionario y la aplicación de la teoría del social imperialismo ruso en Argentina (1968-1984)". Ponencia presentada en las II Jornadas de historia del movimiento obrero y la izquierda, desarrolladas los días 3, 4 y 5 de octubre de 2018 en el Centro Cultural Paco Urondo, Facultad de Filosofía y Letras, Universidad de Buenos Aires.

. (2019). Eugenio Gastiazoro: del MLN al PCR, de la Economía a la Historia (1965-1989). Anuario de la Escuela de Historia de la Universidad Nacional de Rosario. $\mathrm{n}^{\circ} 31$, Rosario, s/p.

RUPAR Brenda (2019). Emergencia y configuración de la corriente maoísta en Argentina. Antecedentes, fundamentos y caracterización (1965-1974). Tesis (Doctoral en Historia), Facultad de Filosofía y Letras de la Universidad de Buenos Aires.

SISKINDOVICH, Santiago (2017). Maoísmo e insurrección popular. La conformación del PCR y de VC en una Argentina en ebullición (1968-1973). Tesis (Licenciatura en Historia), Facultad de Filosofía y Humanidades de la Universidad Nacional de Córdoba.

STARCENBAUM, Marcelo (2016). Itinerarios de Althusser en Argentina: marxismo, comunismo y psicoanálisis. Tesis (Doctorado en Historia), Facultad de 
Humanidades y Ciencias de la Educación - Universidad Nacional de La Plata, diciembre de 2016.

WERNER, Ruth y AGUIRRE, Facundo (2009). El Partido Comunista Revolucionario en los '70. En. Insurgencia Obrera en Argentina 1969-1976. Buenos Aires, IPS, pp. 381-393.

Artigo recebido em 01 de abril de 2020

Aprovado em 20 de junho de 2020

DOI: $10.12957 /$ intellectus.2020.52502 